\title{
Dissociation and Memory for Perpetration Among Convicted Sex Offenders
}

\author{
Kathryn Becker-Blease, PhD \\ Jennifer J. Freyd, PhD
}

\begin{abstract}
SUMMARY. Sex abusers' denial of their offenses poses serious problems for their victims, treatment providers, and researchers. Abusers deny their offenses for many reasons, including avoiding responsibility. It is possible that some abusers do not recall their offenses because of intoxication, head injury, or dissociative symptoms that affect their ability to encode or retrieve information. Self-reports of dissociation during childhood victimization, during the perpetration of victimizing acts, and in everyday life were examined in a sample of 17 convicted sex offenders. Half of the participants reported some forgetting of instances when they had sexually abused another person. Forgetting perpetration was related to both dissociation at the time of the offense and dissociation in everyday life. Dissociating while the participants themselves were being physically
\end{abstract}

Kathryn Becker-Blease is affiliated with Washington State University Vancouver, Psychology Department, VCLS 208U, 14204 NE Salmon Creek Avenue, Vancouver, WA 98686-9600 (E-mail: kblease@vancouver.wsu.edu).

Jennifer J. Freyd is affiliated with the Department of Psychology, 1227 University of Oregon, Eugene, OR 97403-1227 (E-mail: jjf@dynamic.uoregon.edu and jtd@dynamic. uoregon.edu).

This project was funded in part by a graduate student research grant from the Center for the Study of Women in Society at the University of Oregon. Manuscript preparation was supported by the UO Foundation's Fund for Research on Trauma and Oppression.

[Haworth co-indexing entry note]: "Dissociation and Memory for Perpetration Among Convicted Sex Offenders." Becker-Blease, Kathryn, and Jennifer J. Freyd. Co-published simultaneously in Journal of Trauma \& Dissociation (The Haworth Medical Press, an imprint of The Haworth Press, Inc.) Vol. 8, No. 2 , 2007, pp. 69-80; and: Trauma and Dissociation in Convicted Offenders: Gender, Science, and Treatment Issues (ed: Kathryn Quina, and Laura S. Brown) The Haworth Medical Press, an imprint of The Haworth Press, Inc., 2007, pp. 69-80. Single or multiple copies of this article are available for a fee from The Haworth Document Delivery Service [1-800-HAWORTH, 9:00 a.m. - 5:00 p.m. (EST). E-mail address: docdelivery@ haworthpress.com].

Available online at http://jtd.haworthpress.com

(C) 2007 by The Haworth Press, Inc. All rights reserved. doi:10.1300/J229v08n02_05 
or sexually abused as children was related to both dissociation during later perpetration and everyday dissociation as an adult. The results support continued research and clinical work to determine the frequency of dissociative symptoms and amnesia among sex abusers. doi:10.1300/ J229v08n02_05 [Article copies available for a fee from The Haworth Document Delivery Service: 1-800- HAWORTH. E-mail address: < docdelivery@ haworthpress. com> Website: <http://www.HaworthPress.com> (c) 2007 by The Haworth Press, Inc. All rights reserved.]

KEYWORDS. Dissociation, memory, sex offenders, criminal behavior

\section{INTRODUCTION}

Sex abusers' denial, minimization, and amnesia for their actions is a serious impediment to holding abusers accountable, validating survivors' experiences, and preventing future abuse. Sex abusers deny their actions for many reasons, including fear of rejection or punishment. Other abusers acknowledge they must have done something, but claim that they cannot remember what they actually did (Hall, 1996; Marshall, Serran, Marshall, \& Fernandez, 2005). Although clinicians report a high percentage of clients who intentionally malinger, it is possible that some abusers do not recall their offenses because of intoxication, head injury, or dissociative symptoms that affect their ability to encode or retrieve information (Moskowitz, 2004).

It is difficult to know how frequently abusers claim not to have memory for offenses or how many actually are unable to recall memory for offenses they have committed. Alleged perpetrators of all kinds of crimes claim amnesia (see Moskowitz, 2004 for a review), but these claims, of course, are complicated by a strong motivation to maintain innocence during legal proceedings. Even more problematic is the fact that the majority of sex crimes are never brought to the attention of authorities, making it impossible to know how many offenders claim not to recall offenses when confronted informally, or how many are never confronted with abuse they do not recall. Survivors of childhood sexual abuse frequently report not being believed-a phenomenon in which offender denials may play a significant role (Veldhuis \& Freyd, 1999).

In response to the difficulty of treating sex offenders who claim not to remember their offenses, Marshall et al. (2005) published a method for helping convicted sex offenders recover memories of perpetration prior to beginning group treatment. The level of amnesia varied, with 
most offenders having recall for the day of the abuse, but not the offense itself. Offenders were encouraged to recall repeatedly the events leading up to the offense and events occurring just after until they have recalled details of the offense itself. Presumably the offenders in Marshall et al.'s program were motivated to recover memories, as the only way to enter treatment and qualify for early parole was to first recover the memory. When offenders reported memories of the events, their version was compared with police reports and victim statements to ensure accuracy of the reported memories. Marshall et al. (2005) attempted this technique with 22 convicted male sex offenders, including 10 who said they were intoxicated at the time of the offense and six who claimed to have suffered traumatic head injury. Twenty offenders were able to recover substantially accurate memories of their offenses using this technique. Marshall et al. (2005) did not specifically address dissociation as a possible mechanism of amnesia, and suggest that, at least for treatment, the exact cause of amnesia or whether or not it is feigned may be irrelevant.

The question of whether voluntary perpetration of violence can be viewed as "traumatizing" is controversial (MacNair, 2002; Moskowitz, 2004). Although we do not directly address this controversy here, we are interested in perpetrators' dissociative symptoms in general and at the time they are abusing others. For several reasons, it is likely that sex offenders, as a group, are likely to have dissociative experiences, and that these experiences arise during perpetration.

Trauma History. First, sex offenders, as a group, are a highly traumatized population (Barnard, Hankins, \& Robbins, 1992; Simons, Wurtele, \& Heil, 2002). Estimates of rates of sexual abuse history among identified adult sex offenders ranges from $25 \%$ to $70 \%$, and between $40 \%$ and $80 \%$ of adolescent sex offenders. A history of child physical abuse has been reported in approximately $50 \%$ of sex offenders (see Simons et al., 2002 for a review). A history of child abuse is associated with having dissociative experiences in everyday life, and especially during times of stress (Putnam, 1997). Children who used dissociation to cope with their own victimization may activate the same dissociative cognitive processing style at the time they are perpetrating abuse. The contexts are similar, and some offenders may rely on dissociation to block memories of their own victimization experiences that would otherwise inhibit their own abusive actions. As reviewed by Moskowitz (2004), rates of significant dissociative pathology among sex offenders in nonhospitalized settings range from $9 \%$ to $39 \%$. 
Fantasy Absorption. Second, sex offenders often report vivid and intense sexual fantasies that lead up to perpetration of victims. Often, these fantasies are supported by the use of pornographic movies, literature, and photographs. The experience of becoming very absorbed in daydreams, fantasies, and movies is a key component of dissociation. For example, the Dissociative Experiences Scale (Bernstein \& Putnam, 1986) includes an item that asks how frequently respondents, "find that when you are watching television or a movie you become so absorbed in the story that you are unaware of other events happening around them." Another item asks about times, "you become so involved in a fantasy or daydream that is feels as though it were really happening."

Depersonalization and Derealization. Third, sex offenders frequently objectify their victims, so that they do not view them as real people who feel pain. They sometimes report feeling as though they are watching themselves act from outside their bodies, or as if they are seeing the world in a distorted way (e.g., through a fog). Two related aspects of dissociation (that are also seen in some other psychiatric conditions) could be related to these phenomena for some sex offenders. Derealization is an aspect of dissociation that involves seeing the world as "unreal." Depersonalization is a feeling that one's own self is not real. Derealization and depersonalization are often reported together (Bernstein \& Putnam, 1986). A sample DES item is, "Some people sometimes feel as if they are looking at the world through a fog, so that people and objects appear far away or unclear."

Altered Identity. Fourth, it is common for sex offenders to appear to behave quite differently in different contexts. For example, Dennis Radar, convicted of 10 sexually motivated murders, was described this way (Robinson, 2005): "He was a family man, a Cub Scout leader and pastor in his church-all while keeping his double life as the BTK (which stands for 'Bind, Torture, Kill') killer a secret, even from his wife and children." Radar himself referred to his "compartmentalized personalities" (Bardsley, Bell, \& Lohr, n.d.). Compartmentalization-"the separation of areas of awareness and memory from each other" (Putnam, 1997, p. 71)-is a major component of dissociation. It is captured by this DES item (Bernstein \& Putnam, 1986): "Some people find that in one situation they may act so differently compared with another situation that they feel almost as if they were two different people."

Sex offenders are a diverse group that includes people who have significant psychopathy and who abuse drugs and alcohol. We do not argue that all sex offenders are highly dissociative, but that dissociation is one possible mechanism (separate from or in conjunction with psychopathy 
and substance abuse) by which offenders are able to ignore, forget, and/ or deny their abuse. For some, dissociation may serve to perpetuate abuse by facilitating intense deviant fantasies, allowing perpetrators to dehumanize their victims, and behave in socially acceptable ways in day-to-day life that make it difficult for society to believe they could be guilty of sex abuse.

In the current study, we were interested in convicted sex offenders' self-reports of their own dissociation symptoms in general, during abuse experienced during childhood, and during perpetration of abuse. We also examined their own appraisals of their memory for their offenses. Specifically, we hypothesized that dissociation during childhood victimization would be related to dissociation during perpetration. In turn, we hypothesized that dissociation during perpetration would be related to memory impairment for perpetration.

\section{METHOD}

\section{Participants}

Participants were recruited from group therapy sessions at a courtmandated sex offender treatment program. Twenty survey packets were distributed, and seventeen male clients participated. All had been convicted of at least one sex crime against a child or adult. Participants were low income (average annual income $=\$ 9060, S D=6068$ ). Age ranged from 26 to 61 years $(m=43.3, S D=13.7)$. Three participants indicated their highest level of education was less than high school. Twelve indicated obtaining a high school diploma or GED. One participant had a 2-year college degree and one had a 4-year degree. Fourteen participants identified as Non-Hispanic White, one as Hispanic white, and two as Native American/White.

\section{Materials}

Betrayal Trauma Inventory. Participants completed the physical and sexual abuse items (but not the emotional abuse items) from the Betrayal Trauma Inventory (BTI, Freyd, DePrince, \& Zurbriggen, 2001), which assesses detailed information about childhood abuse (prior to age 16). Participants were asked about 34 detailed, behaviorally-defined events. An example physical punishment item asks if "someone punched you with a closed fist, or kicked you, anywhere on your body." A sample 
childhood sexual experiences asks if "someone had you fondle them (for example, touch or caress their genitals or other parts of their body) in a sexual way."

Abuse-Perpetration Inventory. The perpetration section of the AbusePerpetration Inventory (API, Lisak et al., 2000) was used to collect to information about sexual child abuse, adult rape, physical child abuse, and physical violence against an intimate partner. Because the BTI took its initial inspiration from the API, API items are similar to BTI items, in that employ specific, behaviorally-defined descriptions of events. An example item is, "Have you ever performed oral sex on a child close to you?" For all of the questions involving perpetration against a child, questions are repeated for a child "close to you" and "not close to you." Subjects are asked to indicate the number times this event occurred (never, one time, 2-6 times, 6-20 times, 20-100 times, and 100+ times).

Dissociation During Victimization and Perpetration. The 10-item Peritraumatic Dissociation Questionnaire (PDEQ, Marmar, Weiss, \& Metzler, 1997) followed each section of the BTI and API. Participants were asked to consider the last time they had any of the experiences they just responded to (e.g., any of the sexual abuse perpetration items) and answer the PDEQ items thinking about their reactions during that experience and immediately after using a 5-point scale. The PDEQ assesses dissociative experiences, such as "I had moments of losing track of what was going on-I "blanked out" or "spaced out" or in some way felt that I was not part of what was going on." PDEQ item scores were averaged, and had a possible range of 1 to 5 .

Trait Dissociation. The Dissociative Experiences Scale (DES, Bernstein \& Putnam, 1986) is a widely used 28-item self-report survey assessing dissociation in everyday life. Participants rate the amount of times they experienced various experiences, from 0 to $100 \%$ of the time (excluding times they were under the influence of drugs or alcohol). A sample item is "Some people have the experience of driving a car and suddenly realizing that they don't remember what has happened during all or part of the trip. Circle a number to show what percentage of the time this happens to you." DES scores have a possible range of 0 to 100. In past research with criminal offenders, scores greater than 30 or 50 have been used to indicate the presence of pathological dissocation.

Social Desirability. The Marlowe-Crowne Social Desirability Scale (Crowne \& Marlowe, 1960) is comprised of 32 true-false-items. Questions such as, "Before voting, I always examining the candidates thoroughly before deciding" are asked. Socially desirable responses were coded 
"1" and non-socially desirable responses were coded " 0 ," and items were averaged to obtain a mean score.

Memory. Participants were asked four questions about memory for perpetration of sexual abuse. Two questions-"Do you ever find that you've forgotten or blocked out memories about being sexual with a child or unwilling adult?" and "Do thoughts or memories about being sexual with a child or unwilling adult just pop into your head when you are not trying to think about those things?"-used a 5-point response scale from "never" to "almost all the time." Two additional questions"I think I have totally forgotten about at least one time when I was sexual with a child or unwilling adult" and "I have forgotten about parts or at least one time when I was sexual with a child or unwilling adult"-use a 5-point response scale from "strongly disagree" to "strongly agree."

\section{Procedures}

A research assistant announced the opportunity to participate in the study during a group therapy session at a county-funded sexual offender treatment center. The center provides treatment to people convicted of a sexual offense who are mandated to receive treatment during probation or post-prison supervision. Those who consented to participate completed an anonymous survey packet at home and exchanged the completed survey for a $\$ 20$ gift certificate to a local grocery store. A receptionist at the treatment center accepted the completed packets without disclosing the names of participants to treatment or research staff.

\section{RESULTS}

Social Desirability. Social desirability scores ranged from .03 to .83 $(m=43 . p=.21)$ and were not significantly correlated with state or trait dissociation scores, or any of the memory impairment variables.

Victimization and Perpetration History. Fifteen (88\%) participants reported being the victim of childhood physical abuse, including eleven $(65 \%)$ who reported both child sexual and physical victimization, as assessed by the BTI. No participants reported being the victim of sexual abuse only. Because we did not measure emotional abuse, we do not know the rate of childhood emotional mistreatment in this sample. Six (35\%) participants reported sexual abuse perpetration against a child. Eight $(47 \%)$ participants reported both child and adult victims. Three (18\%) participants reported no perpetration, as measured by the API, 
despite having been convicted of a sex crime. Six (35\%) also reported committing physical violence against an intimate partner, and three (18\%) also reported physical abuse against a child.

Dissociation During Victimization and Perpetration. Dissociation during child physical or sexual victimization ranged from 1.00 to $3.90(\mathrm{~m}=$ $1.72, S D=.78)$. Dissociation during perpetration of adult rape or child sex abuse ranged from 1.00 to $3.95(m=1.68, S D=1.02)$. For the twelve participants who experienced both child physical and/or sexual abuse victimization and who had perpetrated a sex crime against a child and/or adult, the correlation between self-reported dissociation during times being victimized and times perpetrating victimization on another was strong $(r=.81, p=001)$.

State and Trait Dissociation. DES scores in this sample were highly variable, ranging from 1.43 to $57.86(m=16.66, S D=15.94)$. Three participants had DES scores greater than 30, including one participant with a score above 50 . No scores were more than 3 standard deviations above the mean. DES scores were highly correlated with dissociative experiences reported during child physical and/or sexual abuse victimization $(r=.82, p<.001)$ and perpetration of sex abuse against an adult and/or child $(r=.73, p=.005)$.

Memory for Perpetration. A significant percentage of participants indicated impaired memory for perpetration. Nine (53\%) participants said, at least once in awhile, they have "forgotten or blocked out memories about being sexual with a child or unwilling adult." Ten (59\%) participants said that, at least once in a while, "thoughts or memories about being sexual with a child or unwilling adult just popped into their heads when they were not trying to think about those things." We did not directly ask if these "thoughts or memories" were of actual abuse the participants had perpetrated. It is possible some participants included times they thought about sexual fantasies or pornography in this figure. Three $(18 \%)$ participants indicated at least some agreement with the statement, "I think I have totally forgotten about at least one time when I was sexual with a child or unwilling adult." Five (29\%) indicated at least some agreement with the statement, "I have forgotten about parts or at least one time when I was sexual with a child or unwilling adult."

Of the three participants who did not admit to any sexual abuse perpetration on the API, two reported that they believed that their memories of abusive behavior were not complete. One said he had "forgotten or blocked out memories about being sexual with a child or unwilling adult" and had "memories about being sexual with a child or unwilling adult just pop into your head when you are not trying to think about 
those things" once in awhile. The second participant responded "sometimes" and "once in awhile" (respectively) to these questions.

The degree to which participants reported they had "forgotten or blocked out memories about being sexual with a child or unwilling adult" was significantly related to both dissociation at the time of perpetration $(r=.79, p=.001)$ and state dissociation $(r=.73, p=.005)$.

\section{DISCUSSION}

This study is, to our knowledge, the first empirical investigation of both dissociation and memory impairment among convicted sex offenders. Our goal was to investigate possible relations between various forms of dissociation (i.e., during victimization, during perpetration, and in everyday life) and memory impairment for sex offending to determine which of these pathways, if any, merit further systematic research. Our results were consistent with the hypothesis that each of these forms of dissociation and memory impairment are related, and the exact relation indeed does deserve further attention.

Due to variability in samples and measurement methods, previous research does not provide definitive estimates of the rates of childhood abuse and dissociation among sex offenders. However, the rates of sexual abuse and dissociation in the current sample were consistent with the available research. Our rate of physical abuse was somewhat higher than that found in two previous studies.

Dissociation, regardless of type, was highly variable. Some offenders appear to have had very few dissociative experiences, and others experience high levels of dissociation. This finding is consistent with theories of dissociation that suggest that both a predisposition to dissociation, as well as traumatizing event(s) are necessary to produce pathological dissociation (Kluft, 1996).

We hypothesized a relation between dissociation during victimization and dissociation during perpetration. Perhaps some offenders who use dissociation during perpetration first learned to dissociate in order to cope with their own childhood victimization. This could also explain how these offenders manage to ignore their own memories and feelings associated with past abuse during the time they are abusing someone else. Consistent with this hypothesis, we found a strong relation between dissociation during victimization and dissociation during perpetration. Dissociation during victimization and perpetration was also highly related to trait dissociation. Although social desirability scores 
were not related to any of the dissociation scores, method variance due to other factors may have contributed to the strength of the relation between these measures, which all relied on the same respondent. The magnitude of the correlations, however, suggests that even if a response set bias or other factors were responsible for some of the variance, there is likely some relation between these variables that deserves further research.

Most of the participants reported some memory impairment for sexually abusive events they had perpetrated. This included both not being able to access memories (or parts of memories) as well as intrusive memories. The fact that significant numbers of convicted offenders report memory impairment seems like an extremely important point to consider when evaluating denials by alleged offenders. Popular belief is that sex abuse victimization is so unforgettable and salient that all true victim accounts will be perfectly consistent and complete. Similar logic would suggest offenders should be equally unable to forget sexually abusing another person. The fact that some offenders report the same kinds of memory impairment as victims, even for events they admit they must have committed, opens the door to a more tolerant stance toward both victims' and offenders' accounts for two reasons. First, it adds to the already ample evidence that despite a belief that no one could forget abuse, in fact, people do. Second, it allows us to more fully consider the possibility that a person guilty of sex abuse may provide a seemingly convincing denial because he does not remember doing it. In fact, he may be able to continue appearing to live a model life because memories of his abusive actions are not part of his everyday consciousness. If we were to take this possibility more seriously, we may be more likely to take victims' claims more seriously as well.

Two of the three participants who did not admit to any perpetration on the API reported some memory impairment for abuse. Because of the anonymous nature of the survey, we were unable to follow-up with those participants to find out if they committed a sex crime that was not assessed by the API, if they believed themselves to be wrongly convicted, or if they lacked sufficient memory to report on precisely what abuse they had perpetrated. We plan to directly ask these follow-up questions in future research, and the findings support further inquiry by law enforcement, lawyers, and treatment providers who work with sex offenders who deny perpetrating abuse.

Finally, dissociation during perpetration and in everyday life were related to memory impairment for perpetration. This was not a perfect correlation. Some participants reported memory impairment, but showed low DES scores. This raises the possibility that other factors could be 
responsible for forgetting (e.g., substance use or head injury) or that the relation between dissociation and memory impairment is more nuanced (e.g., specific dissociative symptoms rather than general dissociation scores are implicated).

This study is limited by factors that have limited other studies of sex offenders. The sample size was small, reflecting the difficulty in identifying and recruiting sex offenders. Nevertheless, strong relations among variables exceeded traditional levels of significance. Sex offenders themselves were the sole reporters for the information obtained. A response set bias could have inflated correlations. Although our social desirability measure was not related to the variables of interest, it is likely offenders' denial and minimization affected their reporting of stigmatizing events. It is difficult to use multi-informant methodologies when the subject of inquiry-internal dissociative processes and secretive crimes-are not visible to observers or reliably measured in other ways. Additional measures of key constructs (e.g., dissociative disorder diagnoses) would strengthen future research on this topic. It will also be important to measure childhood emotional abuse, as recent research suggests such abuse is related to alexithymia (Goldsmith \& Freyd, 2005), which could in turn play a role in perpetrator motivation and denial.

Despite these obstacles, this study is the first to indicate a relation between dissociation and memory impairment among convicted sex offenders. This is an important finding that should be explored further because of clear implications for the identification of abuse victims and offenders, for understanding the etiology of sex offending, and for offender treatment.

\section{REFERENCES}

Bardsley, M., Bell, R., \& Lohr, D. (n.d.). BTK: Birth of a serial killer. Retrieved May 26, 2006, from http://www.crimelibrary.com/serial_killers/unsolved/btk/index_1.html.

Barnard, G. W., Hankins, G. C., \& Robbins, L. (1992). Prior life trauma, post-traumatic stress symptoms, sexual disorders, and character traits in sex offenders: An exploratory study. Journal of Traumatic Stress, 5, 393-420.

Bernstein, E. M., \& Putnam, F. W. (1986). Development, reliability, and validity of a dissociation scale. Journal of Nervous \& Mental Disease, 174, 727-735.

Crowne, D. P., \& Marlowe, D. (1960). A new scale of social desirability independent of psychopathology. Journal of Consulting Psychology, 24, 349-354.

Freyd, J. J., DePrince, A. P., \& Zurbriggen, E. L. (2001). Self-reported memory for abuse depends upon victim-perpetrator relationship. Journal of Trauma and Dissociation, 2, 5-17. 
Goldsmith, R., \& Freyd, J. J. (2005). Awareness for emotional abuse. Journal of Emotional Abuse, 5, 95-123.

Hall, G. C. N. (1996). Theory-based assessment, treatment, and prevention of sexual aggression. New York: Oxford University Press.

Kluft, R. P. (1996). Dissociative identity disorder. In L. K. Michelson \& W. J. Ray (Eds.), Handbook of dissociation: Theoretical, empirical and clinical perspectives (pp. 337-366). New York: Plenum Press.

Lisak, D., Conklin, A., Hopper, J., Miller, P., Altschuler, L., \& Smith, B. (2000). The Abuse-Perpetration Inventory: Development of an assessment instrument for research on the cycle of violence. Family Violence \& Sexual Assault Bulletin, Spring-Summer, 21-30.

MacNair, R. M. (2002). Perpetration-induced traumatic stress. London: Praeger.

Marmar, C. R., Weiss, D. S., \& Metzler, T. J. (1997). The Peritraumatic Dissociative Experiences Questionnaire. In J. P. Wilson \& T. M. Keane (Eds.), Assessing psychological trauma and PTSD (pp. 412-428). New York: Guilford.

Marshall, W. L., Serran, G., Marshall, L. E., \& Fernandez, Y. M. (2005). Recovering memories of the offense in "amnesic" sexual offenders. Sexual Abuse: A Journal of Research and Treatment, 17, 31-38.

Moskowitz, A. (2004). Dissociation and violence: A review of the literature. Trauma, Violence and Abuse, 5, 21-46.

Putnam, F. W. (1997). Dissociation in children and adolescents. New York: Guilford.

Robinson, B. (2005). Beware the friendly neighborhood killer. Retrieved May 26, 2006, 2006, from http://abcnews.go.com/US/LegalCenter/story?id=986939\&page=1.

Simons, D., Wurtele, S. K., \& Heil, P. (2002). Childhood victimization and lack of empathy as predictors of sexual offending against women and children. Journal of Interpersonal Violence, 17, 1291-1307.

Veldhuis, C. B., \& Freyd, J. J. (1999). Groomed for silence, groomed for betrayal. In M. Rivera (Ed.), Fragment by fragment: Feminist perspectives on memory and child sexual abuse (pp. 253-282). Charlottetown, PEI Canada: Gynergy Books.

doi:10.1300/J229v08n02_05 